\section{BMJ Health \& Care Informatics}

\title{
Mothers intention and preference to use mobile phone text message reminders for child vaccination in Northwest Ethiopia
}

\author{
Zeleke Abebaw Mekonnen (1D , ${ }^{1}$ Kassahun Alemu Gelaye, ${ }^{2}$ Martin C. Were, ${ }^{3}$ \\ Binyam Tilahun ${ }^{1}$
}

To cite: Mekonnen ZA, Gelaye KA, Were MC, et al. Mothers intention and preference to use mobile phone text message reminders for child vaccination in Northwest Ethiopia. BMJ Health Care Inform 2021;28:e100193. doi:10.1136/ bmjhci-2020-100193

Received 11 June 2020 Revised 29 December 2020 Accepted 03 February 2021
Check for updates

(C) Author(s) (or their employer(s)) 2021. Re-use permitted under CC BY-NC. No commercial re-use. See rights and permissions. Published by BMJ.

${ }^{1}$ Department of Health Informatics, Institute of Public Health,College of Medicine and Health Sciences, University of Gondar, Gondar, Ethiopia ${ }^{2}$ Department of Epidemiology and Biostatistics, Institute of Public Health, College of Medicine and Health Sciences, University of Gondar, Gondar, Ethiopia

${ }^{3}$ Department of Biomedical Informatics, Vanderbilt University Medical Center, Nashville, Tennessee, USA

Correspondence to Zeleke Abebaw Mekonnen; Zelekeabebaw7@gmail.com

\section{ABSTRACT}

Objectives With the unprecedented penetration of mobile devices in the developing world, mHealth applications are being leveraged for different health domains. Among the different factors that affect the use of mHealth interventions is the intention and preference of end-users to use the system. This study aimed to assess mother's intention and preference to use text message reminders for vaccination in Ethiopia.

Methods A cross-sectional study was conducted among 460 mothers selected through a systematic random sampling technique. Initially, descriptive statistics were computed. Binary logistic regression analysis was also used to assess factors associated with the outcome variable.

Results In this study, of the 456 mothers included for analysis, $360(78.9 \%)$ of mothers have intention to use text message reminders for vaccination. Of these, 270 $(75 \%)$ wanted to receive the reminders a day before the vaccination due date. Mothers aged 35 years or more ( $\mathrm{AOR}=0.35$; 95\% Cl: 0.15 to 0.83 ), secondary education and above (AOR=4.43; 95\% Cl: 2.05 to 9.58), duration of mobile phone use ( $\mathrm{AOR}=3.63 ; 95 \% \mathrm{Cl}: 1.66$ to 7.94 ), perceived usefulness ( $\mathrm{AOR}=6.37 ; 95 \% \mathrm{Cl}: 3.13$ to 12.98) and perceived ease of use ( $\mathrm{AOR}=3.85 ; 95 \% \mathrm{Cl}$ : 2.06 to 7.18) were predictors of intention to use text messages for vaccination.

Conclusion In conclusion, majority of mothers have the intention to use text message reminders for child vaccination. Mother's age, education, duration of mobile phone use, perceived usefulness and perceived ease of use were associated with intention of mothers to use text messages for vaccination. Considering these predictors and user's preferences before developing and testing text message reminder systems is recommended.

\section{BACKGROUND}

Timely completion and uptake of the childhood vaccination is key to reducing the high morbidity and mortality of vaccinepreventable diseases (VPDs) among infants globally. Maintaining reductions in mortality from VPD relies on continued immunisation uptake that is reliant on parental
Summary

What is already known?

- The immunisation programme in Ethiopia is challenged with a lack of effective methods to track vaccination schedules.

- Mobile phone short message service is a widely applicable appointment reminder intervention to improve healthcare.

- For the development and effective implementation of mHealth interventions, considering contextual differences and user preferences are crucial.

\section{What does this paper add?}

- This study determined users intention and preferences in a resource-limited setting which helped to design a locally tailored automated text message reminder system for the immunisation programme in Ethiopia.

- The results of this study were used as an input to design and test the effectiveness of a locally developed automated text message reminder system for the immunisation programme in Ethiopia.

decision-making and subsequent attendance at health facilities. ${ }^{1}$ However, many children still miss scheduled vaccines in the extended programme of immunisation or are being vaccinated after the recommended ages. ${ }^{12}$

Adherence to childhood vaccination schedules is a function of various factors including the information gaps both from the service supply and demand sides. ${ }^{3}$ The immunisation programme is also challenged with a lack of effective methods to track vaccination schedules. ${ }^{4}$ Immunisation programmes usually involve the use of the child health card as a tool for reminding caregivers of children of the dates of their next vaccination. ${ }^{3}$ However, it was observed that the majority of the mothers who missed their vaccination appointment were due to forgetfulness and difficulty in tracking vaccination schedules indicating a need to identify 
more innovative approaches. This necessitates the establishment of an appropriate and uninterrupted vaccine delivery strategy with more focus on demand-side interventions. ${ }^{5-7}$

To date, there is a continuous growth of mobile network coverage and unprecedented penetration of mobile devices globally. ${ }^{8}$ By the end of $2018,5.1$ billion people around the world subscribed to mobile services, accounting for $67 \%$ of the global population. ${ }^{9}$ In the same year, mobile subscribers in Ethiopia reached $44 \% .^{10}$ A study conducted on mobile phone access in Gondar city among pregnant women reported that $76.7 \%$ of mothers owned a mobile phone. Among those women who had mobile phones, $90 \%$ were able to read text messages using their mobile phones. ${ }^{11}$ With these advancements, leveraging mobile health (mHealth) applications in the health sector is becoming popular. ${ }^{8}$

mHealth is the use of mobile phone technology to deliver healthcare. ${ }^{12}$ According to the WHO, mHealth has the ability to transform the delivery of healthcare and bring a paradigm shift in healthcare delivery processes all over the world. ${ }^{13}$ mHealth is now extensively used in healthcare and there is a growing global trend in harnessing this technology for behaviour change, disease surveillance, prevention and control of various health problems and enhancing attendance for health services. Hence, the field of mHealth has been proposed as a potential solution to many of the challenges that developing countries face. ${ }^{13-21}$

mHealth applications and programmes make use of several aspects of mobile technology such as text messaging, voice and video services. ${ }^{12}$ The WHO reported that short message service (SMS) is the the most common mobile phone features used for appointment reminders. ${ }^{13}$ It is widely applicable appointment reminder intervention to improve healthcare-seeking behaviours considering participant characteristics such as forgetfulness and lack of knowledge ${ }^{22-24}$ Mobile phonebased text messaging demonstrates strong potential as a tool for healthcare improvement for several reasons; applicability on almost every model of mobile phone, relatively low cost and widely applicable to a variety of health behaviours and conditions. ${ }^{25} 26$

Implementing new technologies is inherently challenging. According to the non-adoption, abandonment, scale-up, spread and sustainability framework, the condition, the technology, the value proposition, the adopter system (comprising professional staff and clients), the organisational infrastructure, the context and the interaction between all these domains determine effective implementation of new technological innovations. ${ }^{27}$ Evidence also indicated that mHealth initiative success is based on the accessibility, acceptance, effective adaptation to local contexts and strong stakeholder collaboration. ${ }^{28-30}$ It is also important to take into account the diverse environment with cultural and contextual differences to adopt new technological interventions. ${ }^{31-37}$

Among the various factors contributing for the successful implementation of mHealth interventions, end-users perception and value propositions to the new system are crucial worth considering before actual implementation. ${ }^{27353839}$ According to the theory of reasoned action, the adoption of new intervention is dependent on the behavioural intention of users. Effective technology use is also the result of an intention in making the behaviour, and this intention is influenced by the perceived ease of use and perceived usefulness including user's preference. ${ }^{37} 3940$

The programme theory for this study is that clients will use the proposed SMS-based mHealth intervention if they have intention to use the system, the system is designed based on their preference and they believe that it will provide positive results. ${ }^{37}$ Hence, investigating the user's intention and preference is crucial to design and implement more effective mHealth interventions in developing countries including Ethiopia. ${ }^{28} 3141-47$ Therefore, this study aimed to assess the intention and preference of mothers to use mobile phone text message reminders for child vaccination in northwest Ethiopia.

\section{METHODS}

\section{Study design and setting}

A health-facility based cross-sectional study was conducted from 1 October to 26 October 2018 in Gondar city administration, northwest Ethiopia. Gondar city administration has a total of 24 Kebele's (the smallest administrative unit in Ethiopia). From the total kebeles, 13 are urban and 11 are rural kebeles. The city administration had an estimated total population of 390644 . Of these, 12149 were under 1 year of age. The city administration has also a total of 23 public health facilities. ${ }^{48}$

\section{Source and study populations}

The source population consisted of mothers paired with infants attending the vaccination units at health facilities. The study population included those eligible motherinfant pairs who visited the selected health facilities during the study period.

\section{Inclusion and exclusion criteria}

Those mothers of infants who visited vaccination units of health facilities and remaining with at least one vaccination appointment were included. Mothers who resided in the study area for at least 6 months prior to the study period and who owned a mobile phone were included for this particular study. Mothers whose infants had already received the last doses of vaccines were excluded from the study.

\section{Sample size determination and sampling procedures}

We could not find any study conducted in Ethiopia to determine the intention of mothers to use text message reminders for routine vaccination. Therefore, we did a pilot study to determine the proportion of those mothers who have the intention to use the text message reminders and it was found to be $77.6 \%$. Finally, the 
sample size required for this study was determined by considering the following assumptions; proportion of intention to use text message reminder for child vaccination as $77.6 \%$ (from pilot study), 95\% CI and $4 \%$ margin of error. With these assumptions, the sample size was 418 . Taking a $10 \%$ non-response rate, the final sample size was 460 .

All the eight health centres and the comprehensive specialised hospital in Gondar city were included in this study. The sample in each health facility was allocated proportionally to the number of clients who vaccinated their infants in the same period of the previous year. A systematic random sampling technique was applied to select the study participants. To select 460 study participants from the 2058 eligible participants, the sampling interval was calculated to be 4.4 which is rounded off to the nearest whole number 4 . Accordingly, every fourth client who presented to the selected health facilities for their infant's vaccination were included in this study.

\section{Study variables}

The outcome variable was the intention to use text message reminders for vaccination. Based on the technology acceptance model (TAM), perceived ease of use and perceived usefulness were considered as predictor variables for this study. ${ }^{49}$ Additionally, the sociodemographic characteristics of mothers were included as predictors for the outcome of interest.

Intention to use mobile text message reminders was defined as the user's likelihood to use mobile phone text message reminders for child vaccination. ${ }^{31} 4350-52$ Perceived ease of use was defined as the extent to which a person believes that using a particular system (in this case the text message reminder) would be free from effort. ${ }^{31} 435051$ Perceived usefulness was defined as the degree to which a person believes that using a particular system (in this case the text message reminder) would enhance his or her task (in this case timely vaccination of children). ${ }^{31435051}$

Items for the composite variables were measured on a 5-point Likert-type scale ranging from 'strongly disagree' (score 1) to 'strongly agree' (score 5). Item scores for each composite variable were added and divided by the number of items to create a composite variable scale (ranging from score 1 to 5 ) for data analysis. ${ }^{53}{ }^{54}$ Finally, the composite variable score was dichotomised as 'Yes' or 'No' based on the final score. Accordingly, final score of above three (agree and strongly agree) were categorised as 'Yes' while those final scores of three or below (strongly disagree, disagree and neutral) were categorised as 'No'. 5556

The household wealth index was created by principal components analysis, including items on asset ownership, housing characteristics and ownership of animals and farming. The household wealth index was calculated separately for urban and rural residents.

\section{Data collection tools and procedures}

The data collection instrument for this study was adapted from the scales used in the TAM which has four major variables: perceived usefulness, perceived ease of use, behavioural intention and actual use. The scales perceived usefulness and perceived ease of use were adapted from Davis's study ${ }^{51}$ and the scale intention to use was adapted from Venkatesh et al's study ${ }^{55}$ to fit the study context. During adaption, the data collection instrument underwent forward and backward translation. Face and content validity of the data collection instrument was assessed by six experts and the proposed changes from the expert panels were considered for refinement of the data collection instrument.

Then, before the actual data collection, a pilot study was done out of the study area, in the health facilities of Bahir Dar city administration with a sample size of 100. The results of the pilot study were used to assess the validity and reliability of the data collection instrument. The internal consistency for each dimension of the data collection instrument was checked using Cronbach's alpha and scores on perceived usefulness (Cronbach alpha $=0.95$ ), perceived ease of use (Cronbach alpha $=0.91)$ and intention to use text message reminders (Cronbach alpha $=0.93$ ) were deemed acceptable. Finally, nine data collectors and three supervisors were recruited for the actual data collection. Face to face interview technique was used to collect data from eligible study participants using the validated data collection instrument.

\section{Statistical analysis}

The data were checked for completeness, entered into Epi-data V.3.1 and exported to STATA V.14 software for analysis. Descriptive statistics on frequencies and percentages were computed and have been presented using graphs and tables. A binary logistic regression analysis model was used to identify the predictor variables for intention to use text message reminders for child vaccination. Finally, the results were reported as adjusted odds ratio (AOR) with their $95 \%$ CIs.

\section{Multicollinearity and model fit statistics}

The presence of multicollinearity was checked among independent variables using variance inflation factor (VIF) at a cut-off point of 10 . Finally, the Hosmer and Lemeshow goodness of fit test was used to check the model fit.

\section{RESULTS}

\section{Sociodemographic characteristics}

In this study, a total of 460 study participants were included with a response rate of $99.1 \%$. The mean (SD) age of mothers was $27.2(4.9)$ years. As shown in table 1 , $260(57 \%)$ mothers belonged to an age group of 25-34 years. The majority of the mothers were currently married $(90.8 \%)$, orthodox by religion $(87.5 \%)$ and more than 
Table 1 Sociodemographic characteristics of mothers who vaccinated their infants in health facilities of in Gondar city administration, northwest Ethiopia, 2018 ( $n=456)$

\begin{tabular}{|c|c|}
\hline Characteristics & Total (\%) \\
\hline \multicolumn{2}{|l|}{ Age of mother } \\
\hline$\leq 24$ & $138(30.3)$ \\
\hline $25-34$ & $260(57.0)$ \\
\hline$\geq 35$ & $58(12.7)$ \\
\hline \multicolumn{2}{|l|}{ Marital status } \\
\hline Currently married & $414(90.8)$ \\
\hline Currently not married & $42(9.2)$ \\
\hline \multicolumn{2}{|l|}{ Religion } \\
\hline Orthodox & 399 (87.5) \\
\hline Muslim & $45(9.9)$ \\
\hline Others & $12(2.6)$ \\
\hline \multicolumn{2}{|l|}{ Mother's education } \\
\hline No formal education & $62(13.6)$ \\
\hline Primary & $144(31.6)$ \\
\hline Secondary and above & $250(54.8)$ \\
\hline \multicolumn{2}{|l|}{ Mother's occupation } \\
\hline Housewife & $263(57.7)$ \\
\hline Employed & $60(13.2)$ \\
\hline Merchant & 89 (19.5) \\
\hline Others & $44(9.6)$ \\
\hline \multicolumn{2}{|l|}{ Residence } \\
\hline Rural & $28(6.1)$ \\
\hline Urban & $428(93.9)$ \\
\hline \multicolumn{2}{|l|}{ Family size } \\
\hline$<5$ & $304(66.7)$ \\
\hline$\geq 5$ & $152(33.3)$ \\
\hline \multicolumn{2}{|l|}{ Household wealth index } \\
\hline Poor & $153(33.6)$ \\
\hline Middle & $152(33.3)$ \\
\hline Rich & $151(33.1)$ \\
\hline \multicolumn{2}{|c|}{ Distance to health facility (in minutes) } \\
\hline$<15 \min$ & $192(42.1)$ \\
\hline $15-30 \mathrm{~min}$ & $213(46.7)$ \\
\hline$>30 \min$ & $51(11.2)$ \\
\hline
\end{tabular}

half $(54.8 \%)$ of the mothers attained secondary education and above (table 1 ).

Pertaining to the occupation of the mothers, the largest $263(57.7 \%)$ of the total mothers were housewives followed by merchants $89(19.5 \%)$. The study also indicated that the vast majority $(93.9 \%)$ of the mothers have resided in urban kebeles (table 1 ).

\section{Mobile phone utilisation}

Three hundred and twenty-four $(71.1 \%)$ of the mothers have been using mobile phones for more than two years and $232(50.9 \%)$ of the mothers were using regular(standard) mobile phones.
Table 2 Mobile phone utilisation of mothers who vaccinated their infants in health facilities of Gondar city administration, northwest Ethiopia, 2018

\begin{tabular}{|c|c|}
\hline Characteristics & Total (\%) \\
\hline \multicolumn{2}{|c|}{ Duration of mobile phone use } \\
\hline$<1$ year & $54(11.8)$ \\
\hline $1-2$ years & $78(17.1)$ \\
\hline$>2$ years & $324(71.1)$ \\
\hline \multicolumn{2}{|c|}{ Type of current mobile phone } \\
\hline Regular/Standard & $232(50.9)$ \\
\hline Smart & $224(49.1)$ \\
\hline \multicolumn{2}{|c|}{ Changed phone number in the last 12 months } \\
\hline No & $425(93.2)$ \\
\hline Yes & $31(6.8)$ \\
\hline \multicolumn{2}{|c|}{ Have additional phone number } \\
\hline No & $411(90.1)$ \\
\hline Yes & 45 (9.9) \\
\hline
\end{tabular}

Usually experienced mobile network challenges

\begin{tabular}{lc} 
No & $415(91.1)$ \\
Yes & $41(8.9)$ \\
Problem keeping a mobile phone charged & \\
No & $420(92.1)$ \\
Yes & $36(7.9)$ \\
Switch off mobile phone during day time & \\
$\quad$ No & $427(93.6)$ \\
Yes & $29(6.4)$ \\
Can read mobile text message & \\
$\quad$ No & $41(9)$ \\
\hline Yes & $415(91)$ \\
Can send mobile text message & $58(12.7)$ \\
\hline No & $398(87.3)$ \\
\hline Yes & \\
Shared mobile phone with others in the house & \\
\hline No & $500(87.7)$ \\
\hline Yes & $56(12.3)$ \\
\hline
\end{tabular}

Mobile phone network challenges were usually encountered by $41(8.9 \%)$ of the participants and $36(7.9 \%)$ encountered a problem to keep their mobile phones charged. Regarding text message use, 415 (91\%) and 398 $(87.3 \%)$ of the mothers can read and send mobile text messages, respectively. About phone sharing, 56 (12.3\%) shared their mobile phones to household members (table 2).

Intention to use text message reminders for child vaccination In this study, $360(78.9 \%)$ with $95 \%$ CI ( $74.9 \%$ to $82.4 \%)$ of mothers intended to use text message reminders for child vaccination, if offered the opportunity. Three hundred and eighty-eight $(85.1 \%)$ of the mothers perceived the 


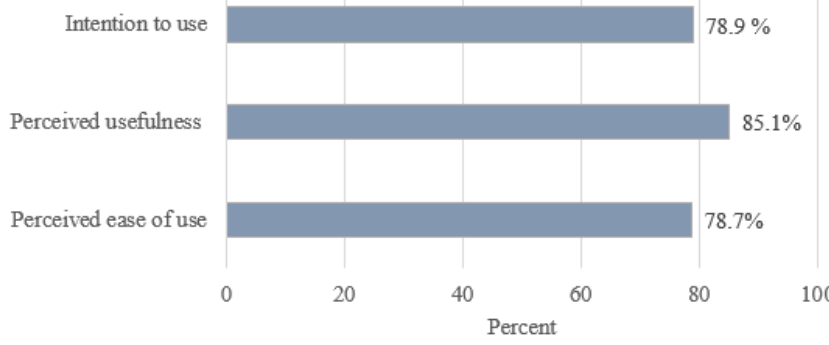

Figure 1 Intention, perceived usefulness and perceived ease of use in using text message reminders for vaccination, Gondar city administration, northwest Ethiopia $(n=456)$.

mobile phone-based text message reminders as useful to child vaccination. Similarly, $359(78.7 \%)$ of the mothers perceived the mobile phone-based text message reminders for child vaccination as easy to use (figure 1 ).

\section{Preference of mothers to receive text message reminders for child vaccination}

Most of the mothers preferred receiving text message reminders starting the first vaccination appointment $(47.8 \%)$ followed by a second vaccination appointment $(31.1 \%)$. Regarding the number of text messages, around two-thirds $(64.2 \%)$ preferred to receive one text message reminder per each vaccination appointment. The study also indicated that three-fourths $(75 \%)$ and $131(36.4 \%)$ of the mothers wanted to receive the text message reminder a day before the due date and on the due date of the vaccination appointment, respectively. Regarding language preference, more than half $(58.1 \%)$ of the mothers would prefer to receive text messages in Amharic (national) language while $38.9 \%$ preferred to receive the text message in both Amharic and English languages (table 3).

\section{Predictors of intention to use text message reminders for child vaccination}

Bivariable and multivariable binary logistic regression analyses were done to determine the association between the intention to use text message reminders and covariates. Accordingly, those variables which had a $\mathrm{p}$ value of less than 0.2 in the bivariable regression analysis (mothers age, mother's educational status, mother occupation, marital status, household wealth index, place of residence, duration of mobile phone use, mobile phone type, perceived ease of use and perceived usefulness) were considered for the multivariable regression analysis.

In the final multivariable logistic regression model, the variables mother age, mother education, duration of mobile phone use, perceived ease of use and perceived usefulness were found to have a significant association with intention of mothers to use text message reminders for vaccination.

As shown in table 4 , mothers above 35 years of age were $65 \%$ less likely (AOR $=0.35$; $95 \%$ CI: 0.15 to 0.83 ) to have the intention to use text message reminders for child
Table 3 Preference of mothers to receive text message reminders for child vaccination in Gondar city administration, northwest Ethiopia, $2018(n=360)$

\begin{tabular}{lc}
\hline Characteristics & Total (\%) \\
\hline Preferred appointment to begin receiving reminders & \\
\hline First appointment & $172(47.8)$ \\
\hline Second & $112(31.1)$ \\
\hline Third & $47(13.1)$ \\
\hline Fourth & $29(8.1)$ \\
\hline Preferred number of text messages per visit & \\
\hline One & $231(64.2)$ \\
\hline Two & $115(31.9)$ \\
\hline Three & $14(3.9)$ \\
\hline Preferred date to receive text message reminders & \\
\hline On due date & $131(36.4)$ \\
\hline A day before due date & $270(75)$ \\
\hline Two days before due date & $82(22.8)$ \\
\hline Three days before due date & $16(4.4)$ \\
\hline Others & $4(1.1)$ \\
\hline Preferred time of the day for receiving text message reminders \\
\hline Morning (06:01-before 12:00) & $86(23.9)$ \\
\hline Afternoon (12:00-18:00) & $147(40.8)$ \\
\hline Evening (18:01-00:00) & $30(8.3)$ \\
\hline Any time & $97(26.9)$ \\
\hline Preferred language & $209(58.1)$ \\
\hline Amharic only & $140(38.9)$ \\
\hline Both Amharic and English & $11(3.1)$ \\
\hline English only & \\
\hline
\end{tabular}

vaccination than those who are less than 25 years of age after controlling for other variables. Mothers who had primary education were 2.7 times more likely $(\mathrm{AOR}=2.75$; 95\% CI: 1.25 to 6.05 ) and who had secondary education and above were 4.4 times more likely $(\mathrm{AOR}=4.43 ; 95 \% \mathrm{CI}$ : 2.05 to 9.58 ) to have intention to use text message reminders for child vaccination than those who had no formal education.

The study also indicated that perceived ease of use has a positive and significant effect on the mother's intention to use text message reminders for child vaccination. Keeping other factors constant, those who perceived the text message reminder as easy to use were 3.8 times more likely (AOR=3.85; 95\% CI: 2.06 to 7.18) to have intention to use text message reminders for child vaccination as compared with their counterparts. Similarly, mothers who perceived the text message reminder as useful were 6.3 times more likely (AOR=6.37; 95\% CI: 3.13 to 12.98) to have intention to use text message reminders for child vaccination as compared with their counterparts.

In the final multivariable model, marital status, occupation, household wealth index and the type of mobile phone mothers are currently using did not have a 
Table 4 Bivariable and multivariable binary logistic regression analysis of factors associated with intention to use text message reminders for child vaccination in Gondar city, northwest Ethiopia, 2018

\begin{tabular}{|c|c|c|c|c|}
\hline \multirow[b]{2}{*}{ Characteristics } & \multicolumn{2}{|c|}{ Intention to use (n) } & \multirow[b]{2}{*}{ COR $(95 \% \mathrm{Cl})$} & \multirow[b]{2}{*}{ AOR $(95 \% \mathrm{Cl})$} \\
\hline & No & Yes & & \\
\hline \multicolumn{5}{|l|}{ Age of mother } \\
\hline$\leq 24$ & 23 & 115 & 1 & 1 \\
\hline $25-34$ & 48 & 212 & 0.88 (0.51 to 1.53$)$ & 0.77 (0.38 to 1.55$)$ \\
\hline$\geq 35$ & 25 & 33 & 0.26 (0.13 to 0.52$)$ & 0.35 (0.15 to 0.83$)$ \\
\hline \multicolumn{5}{|l|}{ Mother's education } \\
\hline No formal education & 33 & 29 & 1 & 1 \\
\hline Primary & 29 & 115 & 4.51 (2.37 to 8.59$)$ & 2.75 (1.25 to 6.05$)$ \\
\hline Secondary and above & 34 & 216 & 7.23 (3.90 to 13.39$)$ & 4.43 (2.05 to 9.58$)$ \\
\hline \multicolumn{5}{|l|}{ Marital status } \\
\hline Currently married & 81 & 333 & 1 & 1 \\
\hline Currently not married & 15 & 27 & 0.44 (0.22 to 0.86$)$ & 0.63 (0.24 to 1.64$)$ \\
\hline \multicolumn{5}{|l|}{ Mother's occupation } \\
\hline Housewife & 60 & 203 & 1 & 1 \\
\hline Employed & 11 & 49 & 1.32 (0.64 to 2.69$)$ & 0.94 (0.37 to 2.39$)$ \\
\hline Merchant & 11 & 78 & 2.09 (1.05 to 4.19$)$ & 1.19 (0.50 to 2.83$)$ \\
\hline Others & 14 & 30 & 0.63 (0.32 to 1.27$)$ & 0.91 (0.36 to 2.31$)$ \\
\hline \multicolumn{5}{|l|}{ Household wealth index } \\
\hline Poor & 50 & 103 & 1 & 1 \\
\hline Middle & 24 & 128 & 2.58 (1.49 to 4.49$)$ & 1.27 (0.60 to 2.68$)$ \\
\hline Rich & 22 & 129 & 2.85 (1.62 to 5.01$)$ & 1.15 (0.50 to 2.61$)$ \\
\hline \multicolumn{5}{|l|}{ Duration of mobile use } \\
\hline$<1$ year & 21 & 33 & 1 & 1 \\
\hline $1-2$ years & 31 & 47 & $0.96(0.47$ to 1.96$)$ & 1.08 (0.45 to 2.61$)$ \\
\hline$>2$ years & 44 & 280 & 4.05 (2.15 to 7.62$)$ & 3.63 (1.66 to 7.94 ) \\
\hline \multicolumn{5}{|c|}{ Type of current mobile phone } \\
\hline Regular/Standard & 66 & 166 & 1 & 1 \\
\hline Smart & 30 & 194 & 2.57 (1.59 to 4.15$)$ & 1.40 (0.69 to 2.88$)$ \\
\hline \multicolumn{5}{|l|}{ Perceived ease of use } \\
\hline Not easy & 50 & 47 & 1 & 1 \\
\hline Easy & 46 & 313 & 7.24 (4.37 to 11.99$)$ & 3.85 (2.06 to 7.18$)$ \\
\hline \multicolumn{5}{|l|}{ Perceived usefulness } \\
\hline Not useful & 37 & 31 & 1 & 1 \\
\hline Useful & 59 & 329 & 6.65 (3.83 to 11.56$)$ & 6.37 (3.13 to 12.98$)$ \\
\hline
\end{tabular}

AOR, adjusted odds ratio; COR, crude odds ratio.

significant association with intention of mothers to use mobile phone text message reminders for child vaccination.

\section{Multicollinearity and model fitness}

A multicollinearity test was performed for the variables included in the final multivariable model. Hence, the variable place of residence had a VIF value of 12.3 and was removed from the final model due to its multicollinearity effect. The final model fitness was also assessed using Hosmer and Lemeshow test. The Hosmer and
Lemeshow test showed that the model fits the data well ( $p$ value of 0.905 ).

\section{DISCUSSION}

The findings of this study showed that mothers have a high intention to use mobile phone text message reminders for their child's vaccination. Mother's age, educational status, duration of mobile phone use, perceived ease of use and perceived usefulness were significantly associated 
with intention of mothers to use mobile phone-based text message reminders for vaccination. Mothers preferred to receive mobile phone-based text messages one day before the due date of vaccination and in Amharic (national) language.

This study indicated that the majority of mothers have intentions to use text message reminders for child vaccination. This finding corroborated findings from a study in Lagos Nigeria. ${ }^{57} \mathrm{~A}$ willingness study on pregnant women in Gondar city also reported consistent findings where around three-fourths of women were willing to receive text messages. ${ }^{11}$ However, this finding was slightly higher than a finding from another study in Nigeria. ${ }^{41}$ On the other hand, this finding is lower than a study finding from Kenya. ${ }^{8}$ The difference might be due to the difference in the information communication technology infrastructure and investment in digitalisation across countries.

In this study, the educational status of mothers was positively associated with their intention to use mobile phonebased text message reminders for child vaccination. This finding is in accordance with other studies. ${ }^{544-59}$ This may be explained by the fact that educated women are likely to be aware of incoming text messages and are likely to read and act on the received messages promptly. Evidence also showed that literacy status was shown to be an issue in text message reminder system implementation that has to be addressed when text message reminder system is being planned for implementation. ${ }^{25}$ A potential drawback to implementing a mobile-phone-based text messaging intervention is that it requires the recipient to have a mobile phone and an adequate level of literacy, marginalising some population groups who could potentially benefit from the mHealth intervention. ${ }^{21}$ In our study population, this could affect around $14 \%$ of women having no formal education.

The study also found that perceived usefulness has a positive significant association with intention of mothers to use text message reminders for child vaccination. This finding is consistent with other studies where users who did not believe in the possible advantages of e-Health were less inclined to use e-Health. ${ }^{5-61}$ End-users need to perceive the system as being useful or they will not attempt to use it regardless of how easy or difficult it is to use. Therefore, during system development, there is a need to ensure that the system will improve the intended health outcomes. ${ }^{25} 62$

The findings also showed that perceived ease of use was positively associated with intention of mothers to use text message reminders for child vaccination. This finding corroborates with the findings of other studies. ${ }^{54}$ 58-60 When users have no or little previous experience of using a system, they usually pay more attention to the system's ease of use. This implies that users would be unwilling to use a new mHealth service regardless of how useful the system would be if they perceive it to be difficult to use. Research also showed that users will stop using mHealth interventions that are not user friendly. ${ }^{54}$ Difficulty in using a new system could be solved if the user thinks that the system will be useful to them. One study reported that training users on the new mobile health technology improves perceived ease of use and, thereby, increases intention to use the actual system. ${ }^{54}$ Hence, deployment of mHealth initiatives may require extra guidance on how to operate and use the new system for improved implementation. ${ }^{25} 62$

Mobile services are mainly designed for individual users, who may have different expectations and needs in accordance with their preferences. To develop an effective text message reminder system for vaccination, parental preferences must be fully understood and taken into consideration before deployment. ${ }^{34}$ In this study, more than half of mothers would like to receive the text message reminders in Amharic (national) language. This finding is consistent with evidence from India. ${ }^{26}$ On the contrary, from studies in Nigeria ${ }^{7457}$ majority of the mothers preferred English language for reminders on their mobile phones which could be attributed to their high literacy levels.

For successful implementation of mHealth programmes, clients should be able to choose when and how frequently they would receive text messages. ${ }^{21}$ The findings of this study indicated that the majority of mothers preferred to receive one text message reminder per each vaccination appointment. The optimal timing most preferred by mothers for receiving the text message reminders is the day preceding the vaccination appointment date which corroborates the findings in other studies. ${ }^{5} 4157$ This might be because sending text messages to mothers 1 day before their vaccination appointments will increase the chances of the messages being seen and help them to get prepared for their child vaccination appointments ahead of time.

This study also showed that marital status, mother's occupation, household wealth index and type of current mobile phone were not found to have a significant association with intention of mothers' to use mobile text messages for child vaccination. In another study, it was also reported that the type of mobile phone did not have a significant association with intention to use SMS reminders. ${ }^{11}$ Thus, the type of mobile phone the mother had and the differences in economic status would not be a major challenge for implementing text message reminder interventions for child vaccination. Though it did not have a significant effect in another study, ${ }^{11}$ the variable place of residence has been removed from the final model due to its multicollinearity effect.

\section{Implications for practice and research}

This study has practical implications in particular for immunisation programme managers. Given the high proportion of mothers who had intention to use mobile phone-based text message reminders for vaccination, incorporating mobile text messages is a promising avenue to strengthen the routine immunisation programme in Ethiopia. If designed appropriately by considering user's preference in terms of frequency, timing and language; 
text message-based mHealth interventions may be an innovative way for engaging users in care for improved child vaccination outcomes. The study also provides a basis for further interventional studies that can develop and assess the effectiveness of mobile text messaging interventions as a tool to improve the routine immunisation programme in Ethiopia.

\section{Limitations}

The findings of this study should be interpreted in light of some limitations. First, we studied intention for text message-based appointment reminder for those who already had a mobile phone and visiting vaccination units of health facilities in northwest Ethiopia. So, the findings may not be generalisable to the population of the entire country particularly for those residing in rural areas.

As most mHealth programmes focus on those with mobile phones, a potential drawback to the use of mobile phone-based text-message-reminders is the potential marginalisation of certain populations, such as those that do not have a mobile phone. However, these limitations may be reduced as mobile technology advances and mobile subscriptions grow in developing countries. This study also did not address the ecological and systemic barriers to implementation beyond user's intention to use the technology which demand further research.

\section{CONCLUSION}

In this study, we found that majority of mothers have intention to use mobile phone text message reminders for child vaccination. Most of the mothers also would like to receive the text message reminders in Amharic language one day before the vaccination due date. Predictors of mothers' intention to use mobile phone text message reminders include mother's age, mother's education, duration of mobile phone use, perceived ease of use and perceived usefulness of the proposed system.

Considering these predictors and user's preferences indicated in this study, the development of an automated mobile phone-based text message reminder system and testing its effectiveness is recommended for the immunisation programme in Ethiopia.

Acknowledgements The authors would like to thank the German Academic Exchange Service (DAAD) and Doris Dukes Charitable Foundation (DDCF) for supporting this study through the University of Gondar. Also, the authors are grateful for the study participants, data collectors, supervisors and stakeholders involved in this study.

Contributors ZAM conceived the study. KAG, MCW and BT guided the design and conduct of the study. All the authors were involved in data analysis and manuscript write-up. All authors read and approved the final manuscript.

Funding This work was supported by the University of Gondar with grant number 57428660 . The University of Gondar has no role in the design, data collection, analysis and interpretation of the study findings.

Competing interests None declared.

Patient consent for publication Not required.

Ethics approval This study obtained ethical approval from the University of Gondar Institutional Ethical Review Board (ref no: 0/N/P/RCS/05/060/2018). Also, study permission was acquired at all levels, and informed written consent was obtained from study participants.

Provenance and peer review Not commissioned; externally peer reviewed.

Data availability statement Data are available upon reasonable request. Data will be available from the corresponding author upon reasonable request.

Open access This is an open access article distributed in accordance with the Creative Commons Attribution Non Commercial (CC BY-NC 4.0) license, which permits others to distribute, remix, adapt, build upon this work non-commercially, and license their derivative works on different terms, provided the original work is properly cited, appropriate credit is given, any changes made indicated, and the use is non-commercial. See: http://creativecommons.org/licenses/by-nc/4.0/.

ORCID iD

Zeleke Abebaw Mekonnen http://orcid.org/0000-0003-2923-468X

\section{REFERENCES}

1 Machingaidze S, Wiysonge CS, Hussey GD. Strengthening the expanded programme on immunization in Africa: looking beyond 2015. PLoS Med 2013;10:e1001405.

2 Patel TA, Pandit NB. Why infants miss vaccination during routine immunization sessions? study in a rural area of Anand district, Gujarat. Indian J Public Health 2011;55:321-3.

$3 \mathrm{FMOH}$. Ethiopia national expanded programme on immunization comprehensive multi- multi - year plan 2016 - 2020 Federal Ministry of Health, Addis Ababa, 2016.

4 Oladepo O, Dipeolu IO, Oladunni O. Nigerian rural mothers' knowledge of routine childhood immunizations and attitudes about use of reminder text messages for promoting timely completion. $J$ Public Health Policy 2019;40:459-77.

5 Odinaka K, Edelu B, Achigbu K. Acceptance of mobile phone short message service for childhood immunisation reminders by Nigerian mothers. Port Harcourt Med J 2018;12:127.

6 Abahussin AA, Albarrak Al. Vaccination adherence: review and proposed model. J Infect Public Health 2016;9:781-9.

7 Akinrinade OT, Ajayi IO, Fatiregun AA. Ownership of mobile phones and willingness to receive childhood immunisation reminder messages among caregivers of infants in Ondo state, south-western Nigeria. South African J Child Heal 2018;12.

8 Kazi AM, Carmichael J-L, Hapanna GW, et al. Assessing mobile phone access and perceptions for Texting-Based mHealth interventions among expectant mothers and child caregivers in remote regions of northern Kenya: a survey-based descriptive study. JMIR Public Health Surveill 2017;3:e5.

9 GSMA. The mobile economy, 2019.

10 Bank TW. Ethiopia digital foundations project, 2019.

11 Endehabtu B, Weldeab A, Were M, et al. Mobile phone access and willingness among mothers to receive a Text-Based mHealth intervention to improve prenatal care in Northwest Ethiopia: crosssectional study. JMIR Pediatr Parent 2018;1:e9.

12 John R, Giudicessi BA. Text messaging as a tool for behavior change in disease prevention and management. Bone 2013;23:1-7.

13 WHO. mHealth new horizons for health through mobile technologies. based on the findings of the second global survey on eHealth, 2011.

14 Lin C-L, Mistry N, Boneh J, et al. Text message reminders increase appointment adherence in a pediatric clinic: a randomized controlled trial. Int J Pediatr 2016;2016:1-6.

15 Georgette N, Siedner MJ, Zanoni B, et al. The acceptability and perceived usefulness of a Weekly clinical SMS program to promote HIV antiretroviral medication adherence in KwaZulu-Natal, South Africa. AIDS Behav 2016;20:2629-38.

16 Jemere AT, Yeneneh YE, Tilahun B, et al. Access to mobile phone and willingness to receive mHealth services among patients with diabetes in Northwest Ethiopia: a cross-sectional study. BMJ Open 2019;9:1-11.

17 Kebede M, Zeleke A, Asemahagn M, et al. Willingness to receive text message medication reminders among patients on antiretroviral treatment in North West Ethiopia: A cross-sectional study. BMC Med Inform Decis Mak 2015;15:1-10.

18 Domek GJ, Contreras-Roldan IL, O'Leary ST, et al. Sms text message reminders to improve infant vaccination coverage in Guatemala: a pilot randomized controlled trial. Vaccine 2016;34:2437-43.

19 Wakadha H, Chandir S, Were EV, et al. The feasibility of using mobilephone based SMS reminders and conditional cash transfers to improve timely immunization in rural Kenya. Vaccine 2013;31:987-93. 
20 Higgs ES, Goldberg AB, Labrique AB, et al. Understanding the role of mHealth and other media interventions for behavior change to enhance child survival and development in low- and middle-income countries: an evidence review. J Health Commun 2014;19 Suppl 1:164-89.

21 Cormick G, Kim NA, Rodgers A, et al. Interest of pregnant women in the use of SMS (short message service) text messages for the improvement of perinatal and postnatal care. Reprod Health 2012;9:1-7.

22 Albino S, Tabb KM, Requena D, et al. Perceptions and acceptability of short message services technology to improve treatment adherence amongst tuberculosis patients in Peru: a focus group study. PLoS One 2014;9:1-6.

23 Oluwatosin A, Ogundeji MO, Ogundeji MO. Experiences, perceptions and preferences of mothers towards childhood immunization reminder/recall in Ibadan, Nigeria: a cross-sectional study. Pan Afr Med J 2015;20:243.

24 Kalan R, Wiysonge CS, Ramafuthole T, et al. Mobile phone text messaging for improving the uptake of vaccinations: a systematic review protocol. BMJ Open 2014;4:1-5.

25 Manakongtreecheep K. SMS-reminder for vaccination in Africa: research from published, unpublished and grey literature. Pan Afr Med J 2017;27:23.

26 Datta SS, Ranganathan P, Sivakumar KS. A study to assess the feasibility of text messaging service in delivering maternal and child healthcare messages in a rural area of Tamil Nadu, India. Australas Med J 2014;7:175-80.

27 Greenhalgh T, Wherton J, Papoutsi C, et al. Beyond adoption: a new framework for theorizing and evaluating nonadoption, abandonment, and challenges to the scale-up, spread, and sustainability of health and care technologies. J Med Internet Res 2017;19:e367.

28 Aranda-Jan CB, Mohutsiwa-Dibe N, Loukanova S. Systematic review on what works, what does not work and why of implementation of mobile health (mHealth) projects in Africa. BMC Public Health 2014;14.

29 VitalWaveconsulting, Vital Wave Consulting, VitalWaveconsulting, Vital Wave Consulting.,Vital Wave Consulting. mHealth in Ethiopia: strategies for a new framework 2011:1-65.

30 World Health Organization. Global diffusion of eHealth: making universal health coverage achievable. Report of the third global survey on eHealth, 2016.

31 Gao S, Krogstie J, Siau K. Developing an instrument to measure the adoption of mobile services. Mob Inf Syst 2011;7:45-67.

32 El-Wajeeh M, H. Galal-Edeen PG, Mokhtar DH. Technology acceptance model for mobile health systems. IOSRJMCA 2014;1:21-33.

33 Bastawrous A, Armstrong MJ. Mobile health use in low- and highincome countries: an overview of the peer-reviewed literature. $J R$ Soc Med 2013;106:130-42.

34 Hofstetter AM, Vargas CY, Kennedy A, et al. Parental and provider preferences and concerns regarding text message reminder/recall for early childhood vaccinations. Prev Med 2013;57:75-80.

35 Campbell JI, Aturinda I, Mwesigwa E, et al. The technology acceptance model for resource-limited settings (TAM-RLS): a novel framework for mobile health interventions targeted to Low-Literacy End-Users in resource-limited settings. AIDS Behav 2017:21:3129-40.

36 InAhlers-Schmidt CR, Chesser AK, Paschal AM, et al. Parent opinions about use of text messaging for immunization reminders. $J$ Med Internet Res 2012;14:e83.

$37 \mathrm{NÖ} \mathrm{G}$, ÖS B. Technology acceptance in health care: an integrative review of predictive factors and intervention programs. Procedia Soc Behav Sci 2015;195.

38 Gurupur VP, Wan TTH. Challenges in implementing mHealth interventions: a technical perspective. Mhealth 2017;3:32.

39 Buabeng-Andoh C. Predicting students' intention to adopt mobile learning: A combination of theory of reasoned action and technology acceptance model. J Res Innov Teach Learn 2018;11.
40 Cho Y-M, Lee S, Islam SMS, et al. Theories applied to m-health interventions for behavior change in low- and middle-income countries: a systematic review. Telemed J E Health 2018;24:727-41.

41 Article O. A comparative analysis of mothers ' preference for specific type of phone-derived reminders for routine immunization appointments in llorin, Nigeria, 2018.

42 Vital Wave Consulting. Mhealth in Ethiopia. strategies for a new framework, 2011.

43 Karkonasasi K, Yu-n C, Mousavi SA. Intention to Use SMS Vaccination Reminder and Management System among Health Centers in Malaysia : The Mediating Effect of Attitude, 2011.

44 Ibraheem RM, Akintola MA. Acceptability of reminders for immunization appointments via mobile devices by mothers in llorin, Nigeria: a cross-sectional study. Oman Med J 2017;32:471-6.

45 Chao C-M. Factors determining the behavioral intention to use mobile learning: an application and extension of the UTAUT model. Front Psychol 2019;10:1652.

46 Lepère $\mathrm{P}$, Touré $\mathrm{Y}$, Bitty-Anderson AM, et al. Exploring the patterns of use and acceptability of mobile phones among people living with HIV to improve care and treatment: cross-sectional study in three francophone West African countries. JMIR Mhealth Uhealth 2019; 7:e13741

47 Zaunbrecher BS, Kowalewski S, Ziefle M. The willingness to adopt technologies: A cross-sectional study on the influence of technical self-efficacy on acceptance. Lect Notes Comput Sci (including Subser Lect Notes Artif Intell Lect Notes Bioinformatics). 2014;8512 LNCS(PART 3): 764-75.

48 Department GTH. Gondar town administration health office report, 2018.

49 Lee Y, Kozar KA, Larsen KRT. The technology acceptance model: past, present, and future. CAIS 2003;12.

50 Sek Y-W, Lau S-H, Teoh K-K, et al. Prediction of user acceptance and adoption of smart phone for learning with technology acceptance model. J. of Applied Sciences 2010;10:2395-402.

51 Davis FD. Perceived usefulness, perceived ease of use, and user acceptance of information technology. MIS Quarterly 1989;13:319.

52 Amoroso DL, Hunsinger S. Measuring the acceptance of Internet technology by consumers. IJEA 2009;1:48-81.

53 Venkatesh V, Davis FD. A model of the antecedents of perceived ease of use: development and test. Decis Sci 1996;27:451-81.

54 Park DY, Goering EM, Head KJ, et al. Implications for training on smartphone medication reminder APP use by adults with chronic conditions: pilot study applying the technology acceptance model. JMIR Form Res 2017;1:e5.

55 Venkatesh V, Morris MG, Davis GB, et al. User acceptance of information technology: toward a unified view. MIS Quarterly 2003;27:425.

56 Gagnon MP, Orruño E, Asua J, et al. Using a modified technology acceptance model to evaluate healthcare professionals' adoption of a new telemonitoring system. Telemedicine and e-Health 2012;18:54-9.

57 Balogun MR, Sekoni AO, Okafor IP, Odukoya OO, et al. Access to information technology and willingness to receive text message reminders for childhood immunisation among mothers attending a tertiary facility in Lagos, Nigeria. S Afr J CH 2012;6.

58 de Veer AJE, Peeters JM, Brabers AEM, et al. Determinants of the intention to use e-health by community dwelling older people. BMC Health Serv Res 2015;15:1-9.

59 Deng Z, Hong Z, Ren C, et al. What predicts patients' adoption intention toward mhealth services in China: Empirical study. JMIR Mhealth Uhealth 2018;6:e172-14.

60 Tao D. Intention to use and actual use of electronic information resources: further exploring technology acceptance model (TAM). AMIA Annu Symp Proc 2009;2009:629-33.

61 Liébana-Cabanillas F, Ramos de Luna I, Montoro-Ríos F. Intention to use new mobile payment systems: a comparative analysis of SMS and NFC payments. Econ Res Istraz 2017;30:892-910.

62 Puhan MA, Chandra D, Mosenifar Z, et al. Trust, perceived risk, perceived ease of use and perceived usefulness as factors related to mHealth technology use. Study Heal Technol Inf 2017;37:784-90. 